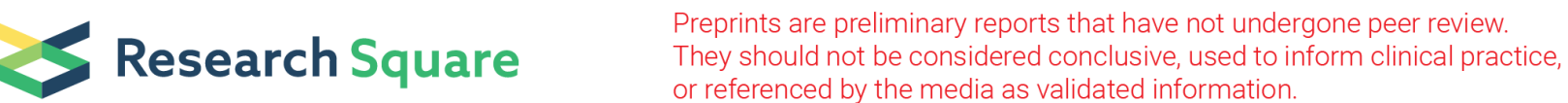

\section{Divergent responses of biomass accumulation and its allocation to the altered precipitation regimes among different degraded grasslands in China}

\section{Tianxue Yang \\ Institute of Grassland Science, Northeast Normal University \\ Junda Chen \\ Institute of Grassland Science, Northeast Normal University \\ Xiaoyue Zhong \\ Institute of Grassland Science, Northeast Normal University \\ Xuechen Yang \\ Institute of Grassland Science, Northeast Normal University \\ Gui Wang \\ Institute of Grassland Science, Northeast Normal University \\ Yuan Yao \\ Institute of Grassland Science, Northeast Normal University \\ Marcelo Sternberg \\ Tel Aviv University \\ Wei Sun ( $\nabla$ sunwei@nenu.edu.cn ) \\ Institute of Grassland Science, Northeast Normal University}

\section{Research Article}

Keywords: precipitation frequency, precipitation amount, degraded grassland, biomass allocation, community composition, mesocosm

Posted Date: March 30th, 2021

DOI: https://doi.org/10.21203/rs.3.rs-243440/v1

License: (c) (i) This work is licensed under a Creative Commons Attribution 4.0 International License. Read Full License

Version of Record: A version of this preprint was published at Plant and Soil on August 8th, 2021. See the published version at https://doi.org/10.1007/s11104-021-05029-1. 


\section{Abstract}

Purpose Climate models predict shifts in precipitation patterns characterized by increased precipitation amount and decreased frequency for semi-arid grasslands in northeast China. However, under these novel climatic conditions, potential differences in plant biomass and its allocation among different degraded grasslands remain unclear.

Methods We conducted a mesocosm experiment to test the effects of higher precipitation amount (increased by $50 \%$ from the long-term mean) and lower frequency (decreased by $50 \%$ ) on plant biomass and allocation in the lightly degraded (LDG), moderately degraded (MDG), and severely degraded grasslands (SDG).

Results Lower precipitation frequency promoted belowground biomass (BGB), while reducing aboveground biomass (AGB) allocation through enhancing soil water variability. Higher precipitation amount enhanced AGB in LDG and MDG, but not in SDG due to less soil inorganic nitrogen. Lower precipitation frequency weakened the positive effects of higher precipitation amount on biomass. Under altered precipitation, adjustment of AGB vs. BGB allocation was the primary biomass allocation strategy in LDG and SDG. However, to maintain water acquirement, plants in MDG preferred to adjust root vertical distribution, and allocated more roots to the deep soil layer where had a relatively stable water source. This strategy was driven by the changes in plant community composition of the dominant species in MDG.

Conclusions The findings of this research emphasized the importance of considering the degradation level of grasslands when predicting the responses of the ecosystem functions to the projected changes in precipitation regime. These findings are critical for making feasible decisions for the sustainable management of degraded grasslands.

\section{Introduction}

General circulation models predict an intensification in the global hydrological cycle, which may be manifest in many ways, such as an increase in annual precipitation amount and/or a decrease in precipitation frequency (IPCC 2013). Such changes have already been observed in many areas including northeast China over the last decades (http://data.cma.cn). Ongoing and future variation in precipitation regimes will strongly alter soil water availability, which is the primary constraint to plant growth in many drought-prone biomes (Gao et al. 2019; Knapp et al. 2001). Most of the studies about the impact of changes in precipitation on plant biomass accumulation focus on aboveground biomass (AGB), with much less attention given to the hidden belowground portion of biomass (BGB) (Zhang et al. 2019a). Considering contrasting aboveground and belowground sensitivity to altered precipitation, this oversight questions the validity of our current understanding of how plants adjust biomass allocation to mitigate abiotic stress, and further consequences on belowground processes, such as soil nutrient cycling and plant-soil feedbacks (Freschet et al. 2018; Wilcox et al. 2015).

As the most widespread vegetation type, grasslands are mainly located in arid and semiarid areas, leading to greater sensitivity to altered precipitation (Knapp et al. 2016). Moreover, grassland plants allocate a large fraction of biomass (33-86\%) into belowground, contributing to an excellent research object of aboveground 
and belowground biomass allocation (Xu et al. 2013). Previous studies focus on natural well-managed grasslands to explore responses of plant biomass and its allocation to altered precipitation (Knapp et al. 2018; Wilcox et al. 2016; Zhang et al. 2020a). However, some $20 \%$ of the world's grasslands are in a severely degraded state; while others have suffered shifts to less-desirable species (Michalk et al. 2018). Because of overgrazing and global climate change, more than $61 \%$ of grasslands in China have experienced salinization and/or desertification to various extents (Zhou et al. 2014). Due to differences in plant community composition and soil properties, the responses of biomass accumulation and its allocation to altered precipitation are likely divergent among grasslands with different degrees of degradation (Dong et al. 2020).

In general, increased precipitation amount promotes AGB through enhancing photosynthetic rate (Ren et al. 2017). Besides, higher precipitation amount is likely to increase soil nitrogen ( $N$ ) mineralization, $N$ availability (Schaeffer et al. 2013), and plant $\mathrm{N}$ acquirement (Ren et al. 2015), which will eventually benefit accumulation of AGB. This positive relationship between precipitation amount and AGB may be strengthened with the intensification of grassland degradation. The reason is that grasslands with higher degradation levels are characterized by more annual plants, which have the ability to grow quickly and actively when water stress is relieved (Fry et al. 2013). However, grasslands with severe degradation status may shift from co-limitation of $\mathrm{N}$ and water to $\mathrm{N}$-limitation if precipitation is increased (Ren et al. 2017). Hence, the promotion of higher precipitation amount to AGB would be weakened by $\mathrm{N}$ limitation in the severely degraded grasslands. In addition, relevant studies pay more attention to altered precipitation amount, rather than precipitation frequency and their interactions. Larger rainfall events resulted from lower precipitation frequency contribute to deeper penetration of soil water and greater soil water retention. The improved soil water environment promotes AGB and further decreases the root/shoot ratio (Heisler-White et al. 2008). On the contrary, larger but fewer rainfall events caused by lower precipitation frequency may increase soil water fluctuation, which is likely to enhance biomass allocation into BGB to alleviate water stress (Post and Knapp 2020; Wilcox et al. 2015). In addition, there should be an interaction between increased precipitation amount and decreased frequency. Lower precipitation frequency may enhance the aforementioned positive effects of higher precipitation amount on biomass accumulation.

Besides aboveground vs. belowground biomass allocation, plants can adjust root vertical distribution along the soil profile to optimize their water and nutrient acquisition (Zhang et al. 2019a). Developing roots in the surface soil is a cost-effective strategy for plants when drought stress is relieved as a result of increment in precipitation amount (Wijk 2011). However, surface soil experienced larger amplitude drying-wetting cycles under the conditions of lower precipitation frequency, causing plants to allocate more root tissue to the deeper soil layers where soil water environment is more stable (Knapp et al. 2008). Moreover, the greater variation in soil moisture in the surface soil may suppress shallow-rooted species and further alter plant communities, resulting in a decline of BGB proportion in the surface soil (Gibson-Forty et al. 2016). Due to differences in proportion of shallow-rooted species among grasslands with various degradation status, the responses of root vertical distribution to altered precipitation patterns in degraded grasslands are likely divergent (Zhang et al. 2019b). Hence, exploring biomass allocation under altered precipitation in different degraded grasslands, and identifying primary allocation strategy are necessary to understand how plants satisfy their resource requirement, which have seldom been reported. 
In this study, we conducted a precipitation manipulation experiment on temperate steppes with varying degradation status (light, moderate and severe degradation) in northern China. We simulated changes in precipitation amount and precipitation frequency, and measured plant species composition, AGB, BGB in different soil layers, with different soil water content, and soil inorganic nitrogen content. We hypothesized that: 1) lower precipitation frequency results in higher soil water variation, causing plants to allocate more biomass to roots so as to alleviate water stress, while higher precipitation amount is likely to promote AGB; 2 ) the promotion of AGB by higher precipitation amount is likely to be weakened by $\mathrm{N}$ limitation in the severely degraded grassland; 3 ) due to differences in plant community compositions, the primary biomass allocation strategies are divergent among different degraded grasslands.

\section{Materials And Methods}

Grassland sites

The studied area $\left(43^{\circ} 47^{\prime} \mathrm{N}, 123^{\circ} 41^{\prime} \mathrm{E}, 345 \mathrm{~m}\right.$ a.s.I.), which has a temperate continental semiarid monsoon climate, is located on the eastern edge of Horqin sandy land, Jilin province, China. Relatively low precipitation defines the region, with annual mean precipitation of about $395.5 \mathrm{~mm}$ and an annual mean temperature of around $6.5^{\circ} \mathrm{C}(1968-2019)$. The annual frost-free period is $130-150$ days. The annual mean wind speed is $3.4 \mathrm{~m} \mathrm{~s}^{-1}$ (Zhou et al. 2008). The original soil type is a Chernozem, with silt and sand dominating its surface layer (Zeng et al. 2018). The original vegetation was meadow steppe dominated by Leymus chinensis. As a result of continuous overgrazing, the dominant species has been gradually replaced by degradation indicator species such as Puccinellia tenuiflora. Many of the fine particles in the soil surface layer have been blown off due to the decline of vegetation cover, resulting in a coarse soil texture. The lower vegetation cover, less precipitation, and higher concentration of alkaline ions in the soil further lead to salinization. Since the 1970s, many ecological restoration projects have been conducted in China, contributing to effective grassland restoration (Liu et al. 2008; Lu et al. 2014). As a result, the studied grasslands now vary in terms of degradation status. Three sites with different degradation levels were chosen, and the distances between sites were less than $2 \mathrm{~km}$ ensuring the same original soil and vegetation type before degradation.

Grassland degradation evaluation

Grassland degradation index (GDI) was widely used to evaluate grassland degradation status (Dong et al. 2020; Zeng et al. 2018). According to the characteristics of the studied grassland, we have modified GDI and further assessed grassland degradation level through calculating the modified GDI (MGDI) for each site using the following equation:

$$
\mathrm{MGDI}=\frac{1}{3}\left(\frac{1}{3} \mathrm{P}_{1}+\frac{2}{3} \mathrm{P}_{2}+\mathrm{P}_{3}\right)+\frac{1}{3}\left(\frac{1}{2} \mathrm{STC}+\frac{1}{2} \mathrm{STN}\right)+\frac{1}{3}\left(\frac{1}{3} \frac{1}{\mathrm{SBD}}+\frac{1}{3} \frac{1}{\mathrm{pH}}+\frac{1}{3} \frac{1}{\mathrm{EC}}\right)
$$

where $P_{1}, P_{2}$ and $P_{3}$ are the relative abundances of annual pioneer species, degradation indicator species and climax species, respectively; STC and STN represent soil total C and N concentration, respectively; SBD is soil bulk density; and EC is soil electrical conductivity. A low value of MGDI represents severe degradation status. 
Based on MGDI value, the studied grassland sites were classified as having three different degradation degrees: light (MGDI: 3.09), moderate (MGDI: 2.74) and severe degradation (MGDI: 1.60).

\section{Experimental protocol}

Experimental grassland mesocosms were established at the beginning of the growing season of 2019 (11 April). The undisturbed soil cores (diameter: $40 \mathrm{~cm}$; height: $50 \mathrm{~cm}$ ) with their standing vegetation were collected in the grasslands with different degradation levels and were put into PVC tubes, which had the same size as the sampling cores. The mesocosms were transported to the Grassland Ecological Research Station of Northeast Normal University, Jilin Province, China. The research station and the studied grasslands are similar in climatic conditions (such as temperature and precipitation) because the distance between the two sites is less than $100 \mathrm{~km}$.

This experiment was established using full factorial design with different degradation levels of grasslands, precipitation amounts and precipitation frequencies. The simulated precipitation amount and frequency were designed based on historical precipitation records and model predictions for future trends. Using daily precipitation data from China Meteorological Data Network (http://data.cma.cn) for the time period of 19682019, we characterized the growing season (May-August) long-term average precipitation amount and frequency for the studied area (Fig. S1). The precipitation event and frequency were defined based on HeislerWhite's study (2008). The precipitation quantity of $305 \mathrm{~mm}$ (long-term average precipitation amount) or $457.5 \mathrm{~mm}$ (increased by $50 \%$ ) was added to mesocosms and distributed as 14-events (long-term average precipitation frequency) or 7-events (decreased by 50\%). 305 and $457.5 \mathrm{~mm}$ of precipitation amount were denoted as control precipitation amount (CPA) and the increased precipitation amount treatment (IPA), respectively. Similarly, 14 and 7 events of precipitation frequency were defined as control precipitation frequency (CPF) and the decreased precipitation frequency treatment (DPF), respectively. Therefore, there were four precipitation patterns in this study: CPF+CPA (14 events and $305 \mathrm{~mm}, 10.4-26.9 \mathrm{~mm}$ rainfall per event), DPF+CPA (7 events and $305 \mathrm{~mm}, 20.8-80.7 \mathrm{~mm}$ rainfall per event), CPF+IPA (14 events and 457.5 $\mathrm{mm}, 15.6-40.4 \mathrm{~mm}$ per event), and DPF+IPA (7 events and $457.5 \mathrm{~mm}, 31.2-121.1 \mathrm{~mm}$ per event). Precipitation events were applied based on the historical seasonal course of rainfall inputs, and the replicate was 7 times per regime for each grassland type. The simulated precipitation experiment was conducted on 1 May 2019. Belowground water was added to each mesocosm with hand sprayers to simulate rainfall events. The precipitation settings were selected to simulate potential precipitation patterns characterized as an increase in growing season precipitation amount and a decline in rainfall frequency. Moreover, the manipulated frequency and amount were within the range of historical values (Fig. S1).

Plant community composition and biomass

On 28 August 2019, plant samples were collected, and all the aboveground plant samples in each mesocosm were harvested and sorted by species. Roots were collected from two soil layers $(0-10$ and $10-30 \mathrm{~cm})$ and were separated from the soil by washing. Only roots in the $0-30 \mathrm{~cm}$ soil layer were considered, because more than $85 \%$ of roots grow in this soil layer (Zhu 2004). All plant samples were dried at $105^{\circ} \mathrm{C}$ for $15 \mathrm{~min}$, and dried at $65^{\circ} \mathrm{C}$ for $48 \mathrm{~h}$, then weighed to calculate the individual aboveground biomass (AGB) and belowground biomass in the $0-10\left(\mathrm{BGB}_{0-10}\right)$ and $10-30 \mathrm{~cm}$ soil layers $\left(\mathrm{BGB}_{10-30}\right)$. 
To elucidate the effects of the altered precipitation patterns on functional groups, all the plant species in the experimental plots were divided into three functional groups: dominant species, gramineous species and forbs (Table S1) (Ma et al. 2019). Further, the relative aboveground biomass (RAGB) of the three functional groups was calculated based on individual biomass.

Soil sample collection

For the measurements of soil properties, we collected 15 soil samples $(0-10 \mathrm{~cm})$ in each degraded grassland using a $2.54 \mathrm{~cm}$ diameter soil core on 25 April 2019. After visible roots were excluded, the moist soil was passed through a $2 \mathrm{~mm}$ mesh sieve and separated into two parts. One part was maintained fresh $\left(4^{\circ} \mathrm{C}\right)$ for the determination of soil water content. The other half was air-dried for the determination of soil $\mathrm{pH}$, electric conductivity, total nitrogen (TN), total carbon (TC), and total organic carbon (TOC). Besides, soil cores with 10 $\mathrm{cm}$ height and $5 \mathrm{~cm}$ diameter were sampled for the measurements of soil bulk density.

During 15-27 June 2019, $4 \mathrm{~cm}$ diameter soil cores were collected in the $0-10$ and $10-30 \mathrm{~cm}$ soil layers in each mesocosm at the beginning (one day after a rainfall event), the middle, and the end (one day before next rainfall event) of one rainfall cycle. The sampled soils were used for the measurements of mean (SWC) and variation (calculated as standard deviation/mean) of soil water content $\left(\mathrm{CV}_{\mathrm{SWC}}\right)$ in the two soil layers in one rainfall cycle.

On 28 August 2019, soil samples of two soil layers (0-10 and 10-30 cm) in each mesocosm were collected and stored in a fridge at $4{ }^{\circ} \mathrm{C}$ after removing the roots, litter and small stones by hand, and sieving with a 2 $\mathrm{mm}$ mesh sieve. The sampled soils were used for the determination of soil $\mathrm{NH}_{4}{ }^{+}$and $\mathrm{NO}_{3}{ }^{-}$concentration.

Soil properties

Soil water content (\%) was measured after drying $10 \mathrm{~g}$ of fresh soil at $105^{\circ} \mathrm{C}$ until a constant weight was achieved. $10 \mathrm{~g}$ fresh soil sample was extracted with $2 \mathrm{~mol} \mathrm{~L}^{-1} \mathrm{KCl}$ solution. The filtered solutions were used to analyze soil $\mathrm{NH}_{4}{ }^{+}$(mg-N kg${ }^{-1}$ dry soil) and $\mathrm{NO}_{3}{ }^{-}\left(\mathrm{mg}^{-} \mathrm{N} \mathrm{kg}^{-1}\right.$ dry soil) content with a continuous flow analyzer (Alliance Flow Analyzer, Futura, Frépillon, France). Soil pH was determined using a 1:5 ratio of airdried soil to deionized water with a pH meter (PhS-3E, Lei Magnetic, Shanghai, China). TN (g kg ${ }^{-1}$ dry soil) and TC ( $\mathrm{g} \mathrm{kg}^{-1}$ dry soil) were analyzed with an elemental analyzer (vario EL cube, Elementar, Langenselbold, Germany). TOC was analyzed with an elemental analyzer (Vario TOC, Elementar, Hanau, Germany) after acidizing the air-dried soil samples with $1 \mathrm{~mol} \mathrm{~L}^{-1} \mathrm{HCl}$.

\section{Data analysis}

In order to investigate interactive effects of precipitation frequency and amount on biomass, the impact values of DPF were evaluated under CPA, represented by impact-DPF under CPA (Eq. 2), and under IPA, which was represented by impact-DPF under IPA (Eq. 3). Similarly, impact-IPA under CPF (Eq. 4), and under DPF were calculated (Fig. 5). 
Impact-DPF under $\mathrm{CPA}(\%)=\frac{\left(\mathrm{X}_{\mathrm{DPF}+\mathrm{CPA}}-\mathrm{x}_{\mathrm{CPF}}+\mathrm{CPA}\right)}{\mathrm{X}_{\mathrm{CPF}+\mathrm{CPA}}}$

Impact-DPF under IPA $(\%)=\frac{\left(\mathrm{X}_{\mathrm{DPF}+\mathrm{PPA}}-\mathrm{X}_{\mathrm{CPF}+\mathrm{IPA}}\right)}{\mathrm{X}_{\mathrm{CPF}}+\mathrm{PPA}}$

Impact-IPA under $\mathrm{CPF}(\%)=\frac{\left(\mathrm{x}_{\mathrm{CPF}+\mathrm{IPA}}-\mathrm{X}_{\mathrm{CPF}}+\mathrm{CPA}\right)}{\mathrm{X}_{\mathrm{CPF}+\mathrm{CPA}}}$

Impact-IPA under DPF $(\%)=\frac{\left(\mathrm{X}_{\mathrm{DPF}+\mathrm{IPA}}-\mathrm{X}_{\mathrm{DPF}+\mathrm{CPA})}\right.}{\mathrm{X}_{\mathrm{DPF}+\mathrm{IPA}}}$

where X-total biomass (TB), AGB and BGB in different soil layers.

In order to explore the biomass allocation strategy, $f_{A G B}\left(A G B / T B\left(A G B\right.\right.$ plus $\left.B G B_{0-30}\right)$ ) and $B G B$ proportion in the $0-10 \mathrm{~cm}$ soil layer $\left(\mathrm{BGB}_{0-10} / \mathrm{BGB}_{0-30}\right)$ were calculated. The changes in biomass fraction caused by the altered precipitation patterns were evaluated, which were represented by sensitivity. Sensitivity of biomass fraction to DPF under CPA $=\left|X_{D P F+C P A}-X_{C P F+C P A}\right|$, sensitivity of biomass fraction to DPF under IPA = $\left|X_{D P F+I P A}-X_{C P F+I P A}\right|$, sensitivity of biomass fraction to IPA under CPF $=\left|X_{C P F+I P A}-X_{C P F+C P A}\right|$, sensitivity of biomass fraction to IPA under DPF $=\left|X_{D P F+I P A}-X_{D P F+C P A}\right|$, where $X$ represents biomass fraction.

Univariate general linear models were used to assess the influence of precipitation manipulation and grassland degradation level on soil environmental factors, plant functional groups, biomass and its allocation. The effects of different precipitation treatments and grassland degradation levels on these variables were examined by one-way ANOVA with LSD test. The treatment differences in the impact value of biomass, and the sensitivity of biomass fraction were analyzed using Independent Samples T-test. The potential influences of precipitation treatments on biomass and its allocation were analyzed using Pearson correlations. We tested for normality using Shapiro-Wilk test and natural log-transformed some datasets to satisfy the assumptions of parametric analyses. All statistical analyses were conducted with SPSS 20.0 software program (SPSS Inc., Chicago, IL, USA). Graphs were generated using the Origin 9.1 (OriginLab Inc., Northampton, MA, USA), Excel 15.25 (Microsoft Inc., Redmond, WA, USA), and R 2.15.3 (R Development Core Team 2012).

\section{Results}

Soil environments

Soil properties of the three degraded grasslands were measured before the initiation of the precipitation manipulation experiment (Table S2). With the intensification of degradation, we detected an increase in $\mathrm{pH}$ value and bulk density, but a decrease in contents of soil total nitrogen, soil total carbon, and soil organic carbon (Table S2).

The mean soil water content (SWC) differed significantly among the three grasslands (Table 1). SWC of 0$10 \mathrm{~cm}$ layer increased from $10.15 \pm 0.51$ to $13.14 \pm 0.97 \%$; whereas it decreased from $12.05 \pm 0.40$ to $10.18 \pm$ $1.17 \%$ at $10-30 \mathrm{~cm}$ soil layer along the increasing degradation level gradient (Table 1). The precipitation frequency treatment (PF) had only a limited effect on SWC, while SWC was significantly promoted by the increased precipitation amount treatment (IPA). There were significant interactive effects of PF and the precipitation amount treatment (PA) on SWC. In addition, in the 10-30 cm soil layer, soil water content 
variation $\left(\mathrm{CV}_{\mathrm{SWC}}\right)$ in the severely degraded grassland was lower than it in the lightly degraded and moderately degraded grasslands under all precipitation patterns (Table 1). The decreased precipitation frequency treatment (DPF) notably increased $\mathrm{CV}_{\mathrm{SWC}}$ in the surface soil, whereas the soil water environment in the deep soil layer was relatively stable. PA had no significant effects on $\mathrm{CV}_{\mathrm{SWC}}$ in the surface soil, however, $\mathrm{CV}_{\text {SWC }}$ in the deep soil layer was decreased considerably by PA. There were no considerable interactions between PF and PA on $\mathrm{CV}_{\text {SWC }}($ Table 1).

Under the four precipitation patterns, the severely degraded grassland had the lowest soil inorganic nitrogen content (SINC) (Table S3). A decline of SINC was detected in mesocosms received DPF. IPA increased SINC in the $0-10 \mathrm{~cm}$ soil layer in the lightly degraded and moderately degraded grasslands, whereas the enhancement effects vanished in the severely degraded grassland. There were significant interactive effects between PF and PA on SINC.

Changes in biomass and plant community composition

Total biomass (TB), aboveground biomass (AGB) and belowground biomass in the different soil layers $\left(\mathrm{BGB}_{0-10}, \mathrm{BGB}_{10-30}\right.$ and $\left.\mathrm{BGB}_{0-30}\right)$ decreased along the increasing degradation gradient (Fig. 1). PF had no significant effects on TB (Table 2), whereas TB was promoted by IPA (Fig. 1a). AGB was lower under DPF (Fig. 1b). However, IPA promoted AGB in the lightly and moderately degraded grasslands, but not for AGB in the severely degraded grassland (Fig. 1b). In addition, DPF promoted BGB $B_{0-10}$ and $B G B_{10-30}($ Fig. 1d, e). Nevertheless, PA had only limited effects on $B G B$, and only $B B_{10-30}$ in the moderately degraded grassland increased (Fig. 1e). There were significant interactive effects of PF and PA on TB, AGB, BGB $0-10$ and $B G B_{0-30}$ (Table 2, Fig. S2). In addition, DPF had greater effects on different biomass components than IPA among the three grasslands (Fig. 2). Plants in the moderately degraded grassland preferred to develop $B_{G B} B_{10-30} u_{n d e r}$ the altered precipitation patterns (Fig. 2).

In order to explore the effects of the altered precipitation on plant community composition, three plant functional groups, dominant species, gramineous species, and forbs, were investigated (Fig. 3). L. chinensis (perennial grass species), P. tenuiflora (perennial grass species) and Chloris virgate (annual grass species) were the dominant species in the lightly degraded, moderately degraded and severely degraded grasslands, respectively (Table S1). Overall, the lightly degraded grassland had the highest value in the relative aboveground biomass (RAGB) of the dominant species, followed by the severely degraded and the moderately degraded grasslands. The altered precipitation had little impact on the plant community composition in the lightly degraded and severely degraded grasslands. However, both DPF and IPA significantly decreased RAGB of the dominant species in the moderately degraded grassland. There were significant interactive effects of PF and PA on the RAGB of the dominant species and forbs (Fig. 3).

Shifts in biomass allocation

Across all precipitation patterns, the fraction of AGB to TB $\left(f_{\mathrm{AGB}}\right)$ increased (from $54.94 \pm 4.88$ to $83.46 \pm$ 4.61) along the increasing degradation level (Fig. 4a). DPF considerably reduced $f_{\text {AGB }}$. We detected a slight increase in $f_{\mathrm{AGB}}$ in the lightly degraded and moderately degraded grasslands under IPA. However, IPA 
decreased $f_{\mathrm{AGB}}$ in the severely degraded grassland. There were interactive effects of PF and PA on $f_{\mathrm{AGB}}$ (Fig. 4a).

On average, $82.69,70.33$ and $76.60 \%$ of BGB were distributed in the $0-10 \mathrm{~cm}$ soil layer in the lightly degraded, moderately degraded and severely degraded grasslands, respectively (Fig. 4b). The precipitation treatments had a limited effect on the root vertical distribution in the lightly degraded and severely degraded grasslands. Nevertheless, in the moderately degraded grassland, both DPF and IPA decreased BGB proportion in the $0-10 \mathrm{~cm}$ soil layer at a significant level (Fig. 4b). There were no significant interactive effects of PF and PA on BGB proportion in the $0-10 \mathrm{~cm}$ soil layer.

In the lightly degraded and severely degraded grasslands, the sensitivities of $f_{\mathrm{AGB}}$ to the altered precipitation patterns were higher than the sensitivities of BGB proportion in the $0-10 \mathrm{~cm}$ soil layer (Fig. 5a, C). However, plants in the moderately degraded grassland preferred to adjust root vertical distribution, rather than alter biomass allocation in AGB vs. BGB under the changing precipitation regime (Fig. 5b).

Influencing factors controlling biomass and its allocation

Higher SWC significantly promoted AGB in the lightly degraded grassland $\left(R^{2}=0.20, P=0.03\right)$ (Fig. 6a) and moderately degraded grassland $\left(R^{2}=0.58, P<0.001\right)$ (Fig. 6b). However, this significantly positive relationship was not detected $\left(R^{2}=0.04, P=0.36\right)$ in the severely degraded grassland (Fig. $\left.6 \mathrm{c}\right)$. BGB $\mathrm{BG}_{0-30}$ was positively correlated with $\mathrm{CV}_{\text {SWC }}$ (lightly degraded grassland: $R^{2}=0.60, P<0.001$; moderately degraded grassland: $R^{2}=0.66, P<0.001$; severely degraded grassland: $R^{2}=0.14, P=0.04$ ).

$f_{A G B}$ was directly controlled by soil water in the three degraded grasslands (Fig. 6). In the moderately degraded grassland, BGB proportion in the $0-10 \mathrm{~cm}$ soil layer was mainly determined by RAGB of the dominant species (Fig. 6b). Moreover, RAGB of the dominant species was negatively impacted by SWC and $\mathrm{CV}_{\text {SwC }}$ (Fig. 6b). These results indicated the changes in the plant community composition induced by altered soil water was the driving factor for root vertical redistribution.

\section{Discussion}

Divergent responses of biomass accumulation to the altered precipitation among grasslands with varying degradation status

DPF resulted in greater $\mathrm{CV}_{\text {SWC }}$ (Table 1), which significantly promoted root growth, whereas suppressed AGB accumulation (Fig. 6). Under DPF, soil water content decreased from $74.84 \%$ to $18.33 \%$ of field capacity under CPA, and declined from $106.57 \%$ to $34.79 \%$ of field capacity under IPA in one rainfall cycle (calculated based on Fig. S3 and water field capacity of each grassland). The greatly unstable soil water environments which were caused by large rainfall events and longer rainfall intervals, posed plants to waterlogging and severe drought (Wang et al. 2019; Zhang et al. 2017). Under such a severe water environment, plants tended to allocate more biomass to roots in order to maintain sufficient uptake of soil water (Didiano et al. 2016). However, lower precipitation frequency has been reported to promote AGB through alleviating water stress in other studies (Gong et al. 2020; Heisler-White et al. 2009). Lower precipitation frequency associated with 
large rainfall events resulted in deeper penetration of rainfall water along the soil profile and less proportional loss to evaporation, which eventually increased the amount of water in the soil for plant uptake (Nielsen and Ball 2015). Whereas, in the present study, DPF did not induce notable enhancement of SWC in the deeper soil layer (Table 1), which could be partially explained by the lower water retention capacity of the studied sandy grasslands. Moreover, longer rainfall intervals (17 days) might counteract the aforementioned positive effects of decreased precipitation frequency on soil water and AGB. Furthermore, the enhancement of higher $\mathrm{CV}_{\text {SWC }}$ on roots in the severely degraded grassland was less than it in the other two grasslands, because the lower SINC limited BGB accumulation (Fig. 6).

IPA enhanced AGB through increasing SWC in the lightly degraded and moderately degraded grasslands (Table 1, Fig. 6a, b). This observation was consistent with the prior study, in which photosynthetic characteristics such as stomatal conductance and estimated leaf chlorophyll concentration were improved by the increment in precipitation amount, which contributed to higher photosynthetic rate and AGB (Ren et al. 2011). However, the positive effect of SWC on aboveground biomass vanished in the severely degraded grassland (Fig. 6c). This result was particularly surprising because plants in the severely degraded grassland were all annuals, which were expected to use water quickly under relieved soil water environments (Zhang et al. 2020b). There are two potential causes for the insensitivity of plants in the severely degraded grassland to IPA. First, compared with the lightly degraded and moderately degraded grasslands, the severely degraded grassland suffered from a much poorer soil nutrient status (Table S3), leading to severe nitrogen colimitation. The nutrient limitation weakened or ended the positive relationship between SWC and AGB was also observed in other studies (Ren et al. 2017; Zhang et al. 2019a). Second, this result could be explained by the meristem limitation hypothesis, which predicts that lower productivity ecosystems have limited capacities to respond to pulses of higher resource availability, due to existing traits of resident species, like fewer seed and bud banks (Knapp and Smith 2001). Our results suggest that the improvement of the projected higher precipitation amount to plant growth in the grasslands under severely degraded status is very limited.

There were interactions between PF and PA on biomass accumulation (Table 2) with DPF weakened or even counteracted the positive effects of IPA on biomass (Fig. S2f-j). Besides, IPA had a negative effect on the positive relationships between PF and BGB (Fig. S2c-e). These phenomena might be partially explained by temporary waterlogging resulted from larger precipitation events under the combined DPF and IPA. It could be further confirmed by higher SWC (104, 91.75 and $123.95 \%$ of field capacity in the lightly degraded, moderately degraded and severely degraded grasslands) at the beginning of one rainfall cycle (Fig. S3). On the one hand, anoxic conditions induced by waterlogging impaired photosynthetic efficiency and antioxidant system of plants, suppressing plant growth (Jiménez et al. 2015). On the other hand, the nutrient demand was supposed to be high under soil anoxia for maintaining plant biomass (Rubio and Lavado 1999). However, lower inorganic nitrogen content in the studied degraded grasslands cannot meet the nutritional needs of plants, resulting in a decrease in plant biomass.

Different patterns of biomass allocation in response to the altered precipitation in the degraded grasslands

DPF associated with unstable soil environment resulted in lower $f_{\mathrm{AGB}}$ (Table 1, Fig. 6). This biomass allocation pattern could be partially explained by the optimal partitioning theory, which suggests plants 
preferentially allocate biomass to the organ that is more efficient in obtaining limited resources (Zhang et al. 2019a). Furthermore, under unstable water environments (higher $\mathrm{CV}_{\mathrm{SWC}}$ ), the suppression of the growth of aboveground reproductive organs limited the water needs of plants so as to alleviate water stress, resulting in lower $f_{\mathrm{AGB}}$ (Freschet et al. 2018). In addition, IPA enhanced AGB, which subsequently caused a higher $f_{\mathrm{AGB}}$ in the lightly degraded and moderately degraded grasslands (Figs. 1b, 4a, b), which was consistent with previous study (Wang et al. 2018). However, a decline of $f_{A G B}$ in the severely degraded grassland under IPA was observed, which may be associated with lower SINC (Fig. 4c). In the water and nitrogen co-limited system, the nitrogen demand of plants would intensify when the water stress was alleviated (Zhang et al. 2019a). Therefore, plants would allocate more biomass to roots which were most critical to relieve nitrogen limitation and improve nitrogen acquisition for plant maintenance (Freschet et al. 2018).

Among the three degraded grasslands, only the moderately degraded grassland preferred to devote more root tissue to the deeper soil layer (Fig. 2), and to adjust root vertical distribution under the altered precipitation patterns (Fig. 4b), which could be attributed to changes in the plant community composition (Fig. 6b). IPA mitigated water limitation in the moderately degraded grassland (SWC increased to $60-70 \%$ of field capacity), and turned plants' competition for water into competition for other resources, such as light (Zhang et al. 2020b). Because of lower height (compared with climax species), the dominant species (P. tenuiflora) in the lower layer had weak light competitiveness, and was further limited by light resource (Hautier et al. 2009), resulting in the decrease in its dominance accordingly. In addition, $P$. tenuiflora, which was a shallow-rooted species, tended to be inhibited by greater $\mathrm{CV}_{S W C}$ in the surface soil resulted from DPF. Having all this in mind, all precipitation treatments decreased RAGB of $P$. tenuiflora in the moderately degraded grassland (Fig. 3). Since the predominant shallow-rooted species had more shallow root proportion compared with the deeprooted species, the decline of $P$. tenuiflora in all precipitation treatments caused a lower shallow root proportion (Fig. 4b). In total, root vertical redistribution in the moderately degraded grassland was a result of plant competition for resources, and it was also a biomass allocation strategy for improving resources utilization efficiency of the plant community. From Table 1, in the moderately degraded grassland, compared with surface soil layer, the deeper soil layer had a relatively stable water environment and provided a harbor for roots under all precipitation treatments. Hence, plants allocated more roots to deeper layer so as to satisfy plant water needs. Furthermore, a general conclusion could be deduced that root vertical redistribution is the primary biomass allocation strategy for the degraded grasslands dominated by the species characterized by lower height than climax species and shallow roots. In addition, DPF and IPA decreased RAGB of the dominant species in MDG (Fig. 3), contributing to higher Shannon-Wiener indexes (increased by 8.70$63.04 \%)$, which potentially improved plant community stability and functional diversity.

Contrastingly, changing precipitation had little effect on plant community composition in the lightly moderately and severely degraded grasslands (Fig. 3). Plant community stability mainly depended on community diversity, dominant species stability and species asynchrony (Kang et al. 2019; Song and Yu 2015). Compared with the moderately degraded (Shannon-Wiener index: 0.46) and severely degraded grasslands (0.15), the lightly degraded grassland had a higher plant diversity (0.67), and further consequences on higher species asynchrony. Higher plant diversity and species asynchrony contributed to higher community stability (Zhou et al. 2020). The positive relationship between plant diversity and community stability was also found in many studies (Kang et al. 2019; Zhang et al. 2016). Moreover, 
rhizomatous grass $L$. chinensis, as the dominant species in the lightly degraded grassland, has welldeveloped roots, and higher stability under resource-limited environments (Bai et al. 2010). Hence, higher community stability could also be attributed to the greater dominant species stability. Similarly, in the severely degraded grassland, $C$. virgata (the dominant species) composed more than $80 \%$ total AGB. The higher height and greater fine roots of $C$. virgata contributed to higher dominant species stability in the severely degraded grassland, and further improved community stability.

Overall, plants in the moderately degraded grassland preferred to adjust root vertical distribution due to unstable community composition attributed to lower dominant species stability. However, biomass allocation in AGB vs. BGB was the primary biomass allocation strategy in the lightly degraded and severely degraded grasslands. The observation was consistent with the result from another study, which showed the altered precipitation had only a limited effect on root vertical distribution (Wilcox et al. 2015). Plants could acquire water and nutrients through mycorrhizal fungi (Li et al. 2019), hence adjusting root vertical distribution was not a preferred biomass allocation strategy.

\section{Conclusions}

To cope with the decreased precipitation frequency associated with increase in soil water content variation, plants in all studied grasslands tended to allocate more biomass into belowground to secure water acquisition ability. The stimulating effects of enhancement in precipitation amount were significant in the lightly degraded and moderately degraded grasslands, but not in the severely degraded grassland due to lower soil inorganic nitrogen content. Lower precipitation frequency offset the positive effects of higher precipitation amount on biomass. Biomass allocation in AGB vs. BGB was the primary biomass allocation strategy in the lightly degraded and severely degraded grasslands. However, plants in MDG primarily adjusted root vertical distribution to satisfy plant water acquirement, which was controlled by the changes in plant community composition. Our study has theoretical and practical significance for predicting the direction and magnitude of changes in grasslands under future climates, for instance, the expected positive effects of the projected increased precipitation amount pattern on restoration of degraded grasslands highly depend on changes in precipitation frequency. The scientific strategies to restore degraded grasslands could be established based on the divergent responses of biomass accumulation and allocation in different degraded grasslands.

\section{Declarations}

Acknowledgements This study was supported by the National Natural Science Foundation of China (31870456, 32001182), Natural Science Foundation of Jilin Province (YDZJ202101ZYTS004). We thank Shicheng Jiang, Xiuquan Yue, and Yanan Li for help during laboratory analyses. We would like to thank the editor and anonymous reviewers for helpful comments on the manuscript.

Funding This study was supported by the National Natural Science Foundation of China (31870456, 32001182), Natural Science Foundation of Jilin Province (YDZJ202101ZYTS004).

Conflicts of interest/Competing interests The authors declare that they have no conflict of interest. 
Availability of data and materials Not applicable.

Code availability Not applicable.

Authors' contributions TY-Conceptualization, Investigation, Formal analysis, Writing-original draft, Writingreview \& editing; JC-Formal analysis, Writing-original draft, Writing-review \& editing; XZ-Investigation, Writingreview \& editing; XY-Investigation, Writing-review \& editing; GW-Investigation, Writing-review \& editing; YYInvestigation; WS-Conceptualization, Formal analysis, Writing-original draft, Writing-review \& editing; MSWriting-review.

\section{References}

Bai Y, Wu J, Clark CM, Naeem S, Pan Q, Huang J, Zhang L, Han X (2010) Tradeoffs and thresholds in the effects of nitrogen addition on biodiversity and ecosystem functioning: evidence from inner Mongolia grasslands. Global Change Biol 16: 358-372. https://doi.org/10.1111/j.1365-2486.2009.01950.x

Didiano TJ, Johnson MTJ, Duval TP (2016) Disentangling the effects of precipitation amount and frequency on the performance of 14 grassland species. PLoS One 11: e0162310.

https://doi.org/10.1371/journal.pone.0162310

Dong S, Shuang Z, Gao J, Boone RB (2020) Enhancing sustainability of grassland ecosystems through ecological restoration and grazing management in an era of climate change on Qinghai-Tibetan Plateau. Agr Ecosyst Environ 287: 106684. https://doi.org/10.1016/j.agee.2019.106684

Freschet GT, Violle C, Bourget MY, Scherer-Lorenzen M, Fort F (2018) Allocation, morphology, physiology, architecture: the multiple facets of plant above- and below-ground responses to resource stress. New Phytol 219: 1338-1352. https://doi.org/10.1111/nph.15225

Fry EL, Manning P, Allen DGP, Hurst A, Everwand G, Rimmler M, Power SA (2013) Plant functional group composition modifies the dffects of precipitation change on grassland dcosystem function. PLoS One 8: e57027. https://doi.org/10.1371/journal.pone.0057027

Gao J, Zhang L, Tang Z, Wu S (2019) A synthesis of ecosystem aboveground productivity and its process variables under simulated drought stress. J Ecol 107: 2519-2531. https://doi.org/10.1111/1365-2745.13218

Gibson-Forty EVJ, Barnett KL, Tissue DT, Power SA (2016) Reducing rainfall amount has a greater negative effect on the productivity of grassland plant species than reducing rainfall frequency. Funct Plant Biol 43: 380-391. http://dx.doi.org/10.1071/FP15174

Gong Y, Zhao D, Ke W, Fang C, Pei J, Sun G, Ye J (2020) Legacy effects of precipitation amount and frequency on the aboveground plant biomass of a semi-arid grassland. Sci Total Environ 705: 13589. https://doi.org/10.1016/j.scitotenv.2019.135899

Hautier Y, Niklaus P, Hector A (2009) Competition for light causes plant biodiversity loss after eutrophication. Science 324: 636-638. https://doi.org/ 10.1126/science.1169640 
Heisler-White JL, Knapp AK, Kelly EF (2008) Increasing precipitation event size increases aboveground net primary productivity in a semi-arid grassland. Oecologia 158: 129-140. https://doi.org/10.1007/s00442-008$1116-9$

Heisler-White JL, Blair JM, Kelly EF, Harmoney K, Knapp AK (2009) Contingent productivity responses to more extreme rainfall regimes across a grassland biome. Global Change Biol 15: 2894-2904. https://doi.org/10.1111/j.1365-2486.2009.01961.x

IPCC (2013) Climate change 2013: the physical science basis contribution of working group I to the fifth assessment report of the intergovernmental panel on climate change. Cambridge University Press, Cambridge, UK.

Jiménez JdlC, Cardoso JA, Dominguez M, Fischer G, Rao I (2015) Morpho-anatomical traits of root and nonenzymatic antioxidant system of leaf tissue contribute to waterlogging tolerance in Brachiaria grasses. Grassl Sci 61: 243-252. https://doi.org/10.1111/grs.12095

Kang S, Li J, Niu J, Zhang Q, Zhang X, Han G, Zhao M, Bao H (2019) Typical steppe ecosystems maintain high stability by decreasing the connections among recovery, resistance, and variability under high grazing pressure. Sci Total Environ 659: 1146-1157. https://doi.org/10.1016/j.scitotenv.2018.12.447

Knapp AK, Smith MD (2001) Variation among biomes in temporal dynamics of aboveground primary production. Science 291: 481-484. https://doi.org/10.1126/science.291.5503.481

Knapp AK, Beier C, Briske DD, Classen AT, Luo Y, Reichstein M, Smith MD, Smith SD, Bell JE, Fay PA, Heisler JL, Leavitt SW, Sherry R, Smith B, Weng E (2008) Consequences of more extreme precipitation regimes for terrestrial ecosystems. Biosci 58: 811-821. https://doi.org/10.1641/B580908

Knapp AK, Ciais P, Smith MD (2016) Reconciling inconsistencies in precipitation-productivity relationships: implications for climate change. New Phytol 214: 41-47. https://doi.org/10.1111/nph.14381

Knapp AK, Carroll CJW, Griffin-Nolan RJ, Slette IJ, Chaves FA, Baur LE, Felton AJ, Gray JE, Hoffman AM, Lemoine NP, Mao W, Post AK, Smith MD (2018) A reality check for climate change experiments: do they reflect the real world? Ecology 99: 2145-2151. https://doi.org/10.1002/ecy.2474

Li J, Meng B, Chai H, Yang X, Song W, Li S, Lu A, Zhang T, Sun W (2019) Arbuscular mycorrhizal fungi alleviate drought stress in $\mathrm{C}_{3}$ (Leymus chinensis) and $\mathrm{C}_{4}$ (Hemarthria altissima) grasses via altering antioxidant enzyme activities and photosynthesis. Front Plant Sci 10: 499.

https://doi.org/10.3389/fpls.2019.00499

Liu H, Yin Y, Tian Y, Ren J, Wang H (2008) Climatic and anthropogenic controls of topsoil features in the semi-arid East Asian steppe. Geophys Res Lett 35: L04401. https://doi.org/10.1029/2007GL032980

Lu X, Mao Q, Gilliam F, Luo Y, Mo J (2014) Nitrogen deposition contributes to soil acidification in tropical ecosystems. Global Change Biol 20: 3790-3801. https://doi.org/10.1111/gcb.12665 
Ma Q, Liu X, Li Y, Li L, Yu H, Qi M, Zhou G, Xu Z (2019) Nitrogen deposition magnifies the sensitivity of desert steppe plant communities to large changes in precipitation. J Ecol 108: 598-610.

https://doi.org/10.1111/1365-2745.13264

Michalk D, Kemp D, Badgery W, Wu J, Zhang Y, Thomassin P (2018) Sustainability and future food security-A global perspective for livestock production. Land Degrad Dev 30: 561-573. https://doi.org/10.1002/ldr.3217

Nielsen UN, Ball BA (2015) Impacts of altered precipitation regimes on soil communities and biogeochemistry in arid and semi-arid ecosystems. Global Change Biol 21: 1407-1421.

https://doi.org/10.1111/gcb.12789

Post AK, Knapp AK (2020) The importance of extreme rainfall events and their timing in a semi-arid grassland. J Ecol 108: 2431-2443. https://doi.org/10.1111/1365-2745.13478

Ren H, Xu Z, Huang J, Clark C, Chen S, Han X (2011) Nitrogen and water addition reduce leaf longevity of steppe species. Ann Bot 107: 145-155. https://doi.org/10.1093/aob/mcq219

Ren H, Xu Z, Huang J, Lv X, Zeng D, Yuan Z, Han X, Fang T (2015) Increased precipitation induces a positive plant-soil feedback in a semi-arid grassland. Plant Soil 389: 211-223. https://doi.org/10.1007/s11104-0142349-5

Ren H, Xu Z, Isbell F, Huang J, Han X, Wan S, Chen S, Wang R, Zeng D, Jiang Y, Fang T (2017) Exacerbated nitrogen limitation ends transient stimulation of grassland productivity by increased precipitation. Ecol Monogr 87: 457-469. https://doi.org/10.1002/ecm.1262

Rubio G, Lavado RS (1999) Acquisition and allocation of resources in two waterlogging-tolerant grasses. New Phytol 143: 539-546. https://doi.org/10.1046/j.1469-8137.1999.00482.x

Schaeffer SM, Sharp E, Schimel JP, Welker JM (2013) Soil-plant N processes in a high arctic ecosystem, NW Greenland are altered by long-term experimental warming and higher rainfall. Global Change Biol 19: 35293539. https://doi.org/10.1111/gcb.12318

Song M, Yu F (2015) Reduced compensatory effects explain the nitrogen-mediated reduction in stability of an alpine meadow on the Tibetan Plateau. New Phytol 207: 70-77. https://doi.org/10.1111/nph.13329

Wang Y, Meng B, Zhong S, Wang D, Ma J, Sun W (2018) Aboveground biomass and root/shoot ratio regulated drought susceptibility of ecosystem carbon exchange in a meadow steppe. Plant Soil 432: 259272. https://doi.org/10.1007/s11104-018-3790-7

Wang J, Shi Y, Ao Y, Yu D, Wang J, Gao S, Knops JMH, Mu C, Li Z (2019) Summer drought decreases Leymus chinensis productivity through constraining the bud, tiller and shoot production. J Agron Crop Sci 205: 554561. https://doi.org/10.1111/jac. 12354

Wijk MTv (2011) Understanding plant rooting patterns in semi-arid systems: an integrated model analysis of climate, soil type and plant biomass. Global Ecol Biogeogr 20: 331-342. https://doi.org/10.1111/j.1466- 
Wilcox KR, Fischer JCV, Muscha JM, Petersen MK, Knapp AK (2015) Contrasting above- and belowground sensitivity of three Great plains grasslands to altered rainfall regimes. Global Change Biol 21: 335-344. https://doi.org/10.1111/gcb.12673

Wilcox KR, Shi Z, Gherardi LA, Lemonie NP, Koerner SE, Hoover DL, Bork E, Byrne KM, Jr JC, Collins SL, Evans S, Gilgen AK, Holub P, Jiang L, Knapp AK, LeCain D, Liang J, Garcia-Palacios P, Penuelas J, Pockman WT, Smith MD, Sun S, White SR, Yahdjian L, Zhu K, Luo Y (2016) Asymmetric responses of primary productivity to precipitation extremes: a synthesis of grassland precipitation manipulation experiments. Global Change Biol 23: 4376-4385. https://doi.org/10.1111/gcb.13706

Xu X, Sherry RA, Niu S, Li D, Luo Y (2013) Net primary productivity and rain-use efficiency as affected by warming, altered precipitation, and clipping in a mixed-grass prairie. Global Change Biol 19: 2753-2764. https://doi.org/10.1111/gcb.12248

Zeng W, Chen J, Liu H, Wang W (2018) Soil respiration and its autotrophic and heterotrophic components in response to nitrogen addition among different degraded temperate grasslands. Soil Biol Biochem 124: 255265. https://doi.org/10.1016/j.soilbio.2018.06.019

Zhang Y, Loreau M, Lu X, He N, Zhang G, Han X (2016) Nitrogen enrichment weakens ecosystem stability through decreased species asynchrony and population stability in a temperate grassland. Global Change Biol 22: 1445-1455. https://doi.org/10.1111/gcb. 13140

Zhang B, Tan X, Wang S, Chen M, Chen S, Ren T, Xia J, Bai Y, Huang J, Han X (2017) Asymmetric sensitivity of ecosystem carbon and water processes in response to precipitation change in a semi-arid steppe. Funct Ecol 31: 1301-1311. https://doi.org/10.1111/1365-2435.12836

Zhang B, Cadotte M, Chen S, Tan X, You C, Ren T, Chen M, Wang S, Li W, Chu C, Jiang L, Bai Y, Huang J, Han X (2019a) Plants alter their vertical root distribution rather than biomass allocation in response to changing precipitation. Ecology 100: e02828. https://doi.org/10.1002/ecy.2828

Zhang H, Gao Y, Tasisa BY, Basin JM, Baskin CC, Lu X, Zhou D (2019b) Divergent responses to water and nitrogen addition of three perennial bunchgrass species from variously degraded typical steppe in Inner Mongolia. Sci Total Environ 647: 1344-1350. https://doi.org/10.1016/j.scitotenv.2018.08.025

Zhang T, Yu G, Chen Z, Hu Z, Jiao C, Yang M, Fu Z, Zhang W, Han L, Fan M, Zhang R, Sun Z, Gao Y, Li W (2020a) Patterns and controls of vegetation productivity and precipitation-use efficiency across Eurasian grasslands. Sci Total Environ 741: 140204. https://doi.org/10.1016/j.scitotenv.2020.140204

Zhang J, Zuo X, Zhao X, Ma J, Medina-Roldán E (2020b) Effects of rainfall manipulation and nitrogen addition on plant biomass allocation in a semiarid sandy grassland. Sci Rep 10: 9026.

https://doi.org/10.1038/s41598-020-65922-0 
Zhou R, Li Y, Zhao H, Drake S (2008) Desertification effects on C and N content of sandy soils under grassland in Horqin, northern China. Geoderma 145: 370-375.

https://doi.org/10.1016/j.geoderma.2008.04.003

Zhou L, Zhou X, Zhang B, Lu M, Luo Y, Liu L, Li B (2014) Different responses of soil respiration and its components to nitrogen addition among biomes: a meta-analysis. Global Change Biol 20: 2332-2343. https://doi.org/10.1111/gcb.12490

Zhou M, Yang Q, Zhang H, Yao X, Zeng W, Wang W (2020) Plant community temporal stability in response to nitrogen addition among different degraded grasslands. Sci Total Environ 729: 138886.

https://doi.org/10.1016/j.scitotenv.2020.138886

Zhu T (2004) Biological ecology of Leymus chinensis. Jilin Science and Technology Press, Changchun (In Chinese)

\section{Tables}

Table 1 Variables of mean (SWC) and variation $\left(\mathrm{CV}_{S W C}\right)$ of soil water content under the four precipitation patterns in the lightly degraded (LDG), moderately degraded (MDG) and severely degraded grasslands (SDG). CPF-control precipitation frequency, DPF-the decreased precipitation frequency treatment, CPA-control precipitation amount, IPA-the increased precipitation amount treatment. Different lowercase letters indicate significant differences at $P<0.05$ level among the precipitation patterns in an identical soil layer in each grassland by multicomparison of LSD test. $P$ values of ANOVA results in the univariate GLMs for the effects of degradation level of grassland (DL), precipitation frequency treatment (PF) and precipitation amount treatment $(\mathrm{PA})$, and their interactive effects on two variables are presented 


\begin{tabular}{|c|c|c|c|c|c|c|c|c|}
\hline \multirow[t]{2}{*}{ Variables } & \multirow{2}{*}{$\begin{array}{l}\text { Soil } \\
\text { layer } \\
(\mathrm{cm})\end{array}$} & \multirow{2}{*}{$\begin{array}{l}\text { Degraded } \\
\text { grasslands }\end{array}$} & \multicolumn{4}{|c|}{ Precipitation patterns } & \multicolumn{2}{|c|}{ ANOVA results } \\
\hline & & & $\mathrm{CPF}+\mathrm{CPA}$ & $\mathrm{DPF}+\mathrm{CPA}$ & $\mathrm{CPF}+\mathrm{IPA}$ & DPF+IPA & & \\
\hline \multirow[t]{9}{*}{$\begin{array}{l}\text { SWC } \\
(\%)\end{array}$} & \multirow[t]{5}{*}{$\begin{array}{l}0- \\
10\end{array}$} & \multirow[t]{2}{*}{ LDG } & \multirow[t]{2}{*}{$\begin{array}{l}9.10 \pm \\
0.32 \mathrm{c}\end{array}$} & \multirow[t]{2}{*}{$\begin{array}{l}7.27 \pm \\
0.50 \mathrm{~d}\end{array}$} & \multirow[t]{2}{*}{$\begin{array}{l}11.28 \pm \\
0.42 \mathrm{~b}\end{array}$} & \multirow[t]{2}{*}{$\begin{array}{l}12.93 \pm \\
0.54 a\end{array}$} & $\begin{array}{l}\mathrm{DL}:< \\
0.001\end{array}$ & $\begin{array}{l}\text { DL } \times \\
\text { PF: } \\
0.194\end{array}$ \\
\hline & & & & & & & PF: & $\mathrm{DL} \times$ \\
\hline & & \multirow[t]{2}{*}{ MDG } & \multirow[t]{2}{*}{$\begin{array}{l}9.94 \pm \\
0.34 \mathrm{c}\end{array}$} & \multirow[t]{2}{*}{$\begin{array}{l}9.29 \pm \\
0.20 \mathrm{c}\end{array}$} & \multirow[t]{2}{*}{$\begin{array}{l}13.57 \pm \\
0.50 a\end{array}$} & \multirow[t]{2}{*}{$\begin{array}{l}12.10 \pm \\
0.49 \mathrm{~b}\end{array}$} & 0.784 & $\begin{array}{l}\text { PA: } \\
0.247\end{array}$ \\
\hline & & & & & & & $\begin{array}{l}P A:< \\
0.001\end{array}$ & $\begin{array}{l}\text { PF } \times \\
\text { PA: }< \\
0.001\end{array}$ \\
\hline & & SDG & $\begin{array}{l}10.08 \pm \\
1.72 \mathrm{bc}\end{array}$ & $\begin{array}{l}9.88 \pm \\
0.93 \mathrm{c}\end{array}$ & $\begin{array}{l}14.01 \pm \\
0.47 \mathrm{~b}\end{array}$ & $\begin{array}{l}18.58 \pm \\
0.91 \mathrm{a}\end{array}$ & & $\begin{array}{l}\text { DL } \times \\
\text { PF } \times \\
\text { PA: } \\
0.001\end{array}$ \\
\hline & \multirow[t]{4}{*}{$\begin{array}{l}10- \\
30\end{array}$} & LDG & $\begin{array}{l}11.05 \pm \\
0.75 b\end{array}$ & $\begin{array}{l}10.26 \pm \\
0.48 b\end{array}$ & $\begin{array}{l}13.82 \pm \\
0.22 \mathrm{a}\end{array}$ & $\begin{array}{l}13.07 \pm \\
0.21 \mathrm{a}\end{array}$ & $\begin{array}{l}\mathrm{DL}:< \\
0.001\end{array}$ & $\begin{array}{l}\text { DL } \times \\
\text { PF: }< \\
0.001\end{array}$ \\
\hline & & \multirow[t]{2}{*}{ MDG } & \multirow[t]{2}{*}{$\begin{array}{l}9.83 \pm \\
0.38 \mathrm{~b}\end{array}$} & \multirow[t]{2}{*}{$\begin{array}{l}9.60 \pm \\
0.48 \mathrm{~b}\end{array}$} & \multirow[t]{2}{*}{$\begin{array}{l}13.46 \pm \\
0.77 a\end{array}$} & \multirow[t]{2}{*}{$\begin{array}{l}13.99 \pm \\
0.35 a\end{array}$} & $\begin{array}{l}P F:< \\
0.001\end{array}$ & $\begin{array}{l}\text { DL } \times \\
\text { PA: }< \\
0.001\end{array}$ \\
\hline & & & & & & & $\begin{array}{l}\text { PA: < } \\
0.001\end{array}$ & $\begin{array}{l}\text { PF } \times \\
\text { PA: }< \\
0.001\end{array}$ \\
\hline & & SDG & $\begin{array}{l}6.74 \pm \\
0.70 \mathrm{~b}\end{array}$ & $\begin{array}{l}6.70 \pm \\
1.14 \mathrm{~b}\end{array}$ & $\begin{array}{l}8.75 \pm \\
0.38 b\end{array}$ & $\begin{array}{l}18.53 \pm \\
0.48 \mathrm{a}\end{array}$ & & $\begin{array}{l}\text { DL } \times \\
\text { PF } \times \\
\text { PA: } \\
<0.001\end{array}$ \\
\hline \multirow[t]{6}{*}{$C V_{\text {SWC }}$} & \multirow[t]{5}{*}{$\begin{array}{l}0- \\
10\end{array}$} & \multirow[t]{2}{*}{ LDG } & \multirow[t]{2}{*}{$\begin{array}{l}0.36 \pm \\
0.04 \mathrm{c}\end{array}$} & \multirow[t]{2}{*}{$\begin{array}{l}0.60 \pm \\
0.05 \mathrm{~b}\end{array}$} & \multirow[t]{2}{*}{$\begin{array}{l}0.34 \pm \\
0.05 c\end{array}$} & \multirow[t]{2}{*}{$\begin{array}{l}0.73 \pm \\
0.04 \mathrm{a}\end{array}$} & $\begin{array}{l}\text { DL: } \\
0.075\end{array}$ & $\begin{array}{l}\text { DL } \times \\
\text { PF: } \\
0.991\end{array}$ \\
\hline & & & & & & & $P F:<$ & $D L \times$ \\
\hline & & \multirow[t]{2}{*}{ MDG } & $\begin{array}{l}0.29 \pm \\
0.04 \mathrm{c}\end{array}$ & $\begin{array}{l}0.66 \pm \\
0.04 \mathrm{a}\end{array}$ & $\begin{array}{l}0.28 \pm \\
0.04 \mathrm{c}\end{array}$ & $\begin{array}{l}0.53 \pm \\
0.02 \mathrm{~b}\end{array}$ & 0.001 & $\begin{array}{l}\text { PA: } \\
0.289\end{array}$ \\
\hline & & & & & & & $\begin{array}{l}\text { PA: } \\
0.929\end{array}$ & $\begin{array}{l}\text { PF x } \\
\text { PA: } \\
0.322\end{array}$ \\
\hline & & SDG & $\begin{array}{l}0.31 \pm \\
0.04 \mathrm{c}\end{array}$ & $\begin{array}{l}0.72 \pm \\
0.15 a\end{array}$ & $\begin{array}{l}0.43 \pm \\
0.05 \mathrm{bc}\end{array}$ & $\begin{array}{l}0.62 \pm \\
0.02 \mathrm{~b}\end{array}$ & & $\begin{array}{l}\text { DL } \times \\
\text { PF } \times \\
\text { PA: } \\
0.058\end{array}$ \\
\hline & $\begin{array}{l}10- \\
30\end{array}$ & LDG & $\begin{array}{l}0.36 \pm \\
0.07 a\end{array}$ & $\begin{array}{l}0.37 \pm \\
0.03 a\end{array}$ & $\begin{array}{l}0.20 \pm \\
0.01 \mathrm{~b}\end{array}$ & $\begin{array}{l}0.35 \pm \\
0.03 \mathrm{a}\end{array}$ & $\begin{array}{l}\mathrm{DL}: \\
0.001\end{array}$ & $\begin{array}{l}\text { DL } \times \\
\text { PF: }\end{array}$ \\
\hline
\end{tabular}




\begin{tabular}{lllll} 
MDG & $0.32 \pm$ & $0.41 \pm$ & $0.27 \pm$ & $0.25 \pm$ \\
& $0.09 \mathrm{ab}$ & $0.04 \mathrm{a}$ & $0.03 \mathrm{ab}$ & $0.02 \mathrm{~b}$ \\
& & & & \\
& & & & \\
& & & & \\
SDG & $0.19 \pm$ & $0.27 \pm$ & $0.20 \pm$ & $0.12 \pm$ \\
& $0.04 \mathrm{a}$ & $0.06 \mathrm{a}$ & $0.07 \mathrm{a}$ & $0.02 \mathrm{a}$ \\
& & & & \\
\hline
\end{tabular}

\begin{tabular}{|ll|} 
& 0.527 \\
PF: & DL $\times$ \\
0.181 & PA: \\
& 0.860 \\
\hline PA: & PF $\times$ \\
0.004 & PA: \\
& 0.496 \\
& DL $\times$ \\
& PF $\times$ \\
& PA: \\
& 0.072 \\
\hline
\end{tabular}

Table $2 P$ values of ANOVA results in the univariate GLMs for the effects of degradation level of grassland $(\mathrm{DL})$, precipitation frequency (PF) and precipitation amount (PA), and their interactions on total biomass (TB), aboveground biomass (AGB), belowground biomass in the $0-30 \mathrm{~cm}$ soil layer $\left(\mathrm{BGB}_{0-30}\right)$, belowground biomass in the $0-10 \mathrm{~cm}$ soil layer $\left(\mathrm{BGB}_{0-10}\right)$, and belowground biomass in the $10-30 \mathrm{~cm}$ soil layer $\left(\mathrm{BGB}_{10-}\right.$ 30)

\begin{tabular}{|llllllll|}
\hline Variables & $\mathrm{DL}$ & $\mathrm{PF}$ & $\mathrm{PA}$ & $\mathrm{DL} \times \mathrm{PF}$ & $\mathrm{DL} \times \mathrm{PA}$ & $\mathrm{PF} \times \mathrm{PA}$ & $\mathrm{DL} \times \mathrm{PF} \times \mathrm{PA}$ \\
$\mathrm{TB}$ & $<\mathbf{0 . 0 0 1}$ & 0.295 & $<\mathbf{0 . 0 0 1}$ & $\mathbf{0 . 0 1 6}$ & $\mathbf{0 . 0 4 5}$ & $<0.001$ & 0.195 \\
$\mathrm{AGB}$ & $<\mathbf{0 . 0 0 1}$ & $<0.001$ & $<0.001$ & 0.787 & $\mathbf{0 . 0 0 5}$ & $<0.001$ & 0.712 \\
\hline $\mathrm{BGB}_{0-30}$ & $<\mathbf{0 . 0 0 1}$ & $<0.001$ & 0.066 & $<0.001$ & 0.187 & $\mathbf{0 . 0 0 2}$ & $\mathbf{0 . 0 0 3}$ \\
$\mathrm{BGB}_{0-10}$ & $<\mathbf{0 . 0 0 1}$ & $<0.001$ & 0.911 & $<0.001$ & 0.156 & $<0.001$ & $\mathbf{0 . 0 0 1}$ \\
$\mathrm{BGB}_{10-30}$ & $<\mathbf{0 . 0 0 1}$ & $<\mathbf{0 . 0 0 1}$ & $<\mathbf{0 . 0 0 1}$ & $<0.001$ & $\mathbf{0 . 0 0 1}$ & 0.463 & 0.722 \\
\hline
\end{tabular}

\section{Figures}


(a)
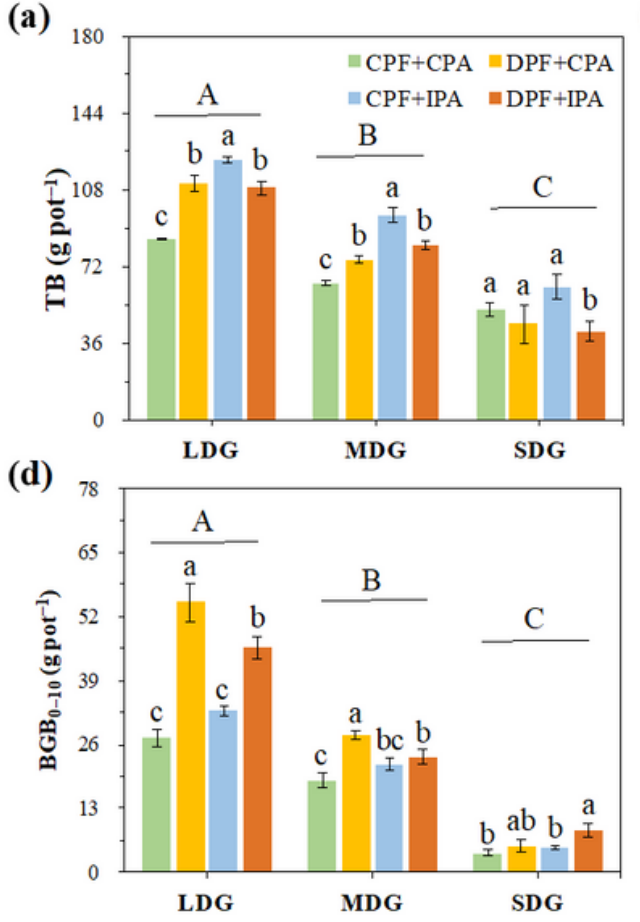

(b)

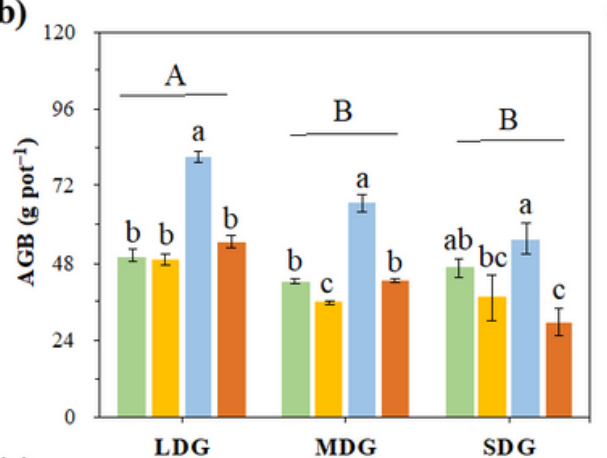

(e)

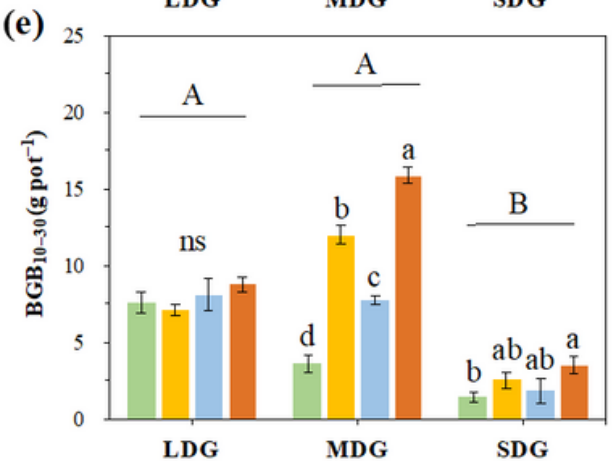

(c)

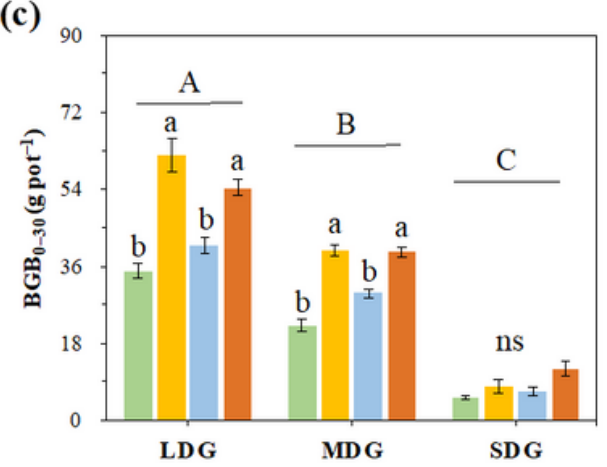

\section{Figure 1}

Responses of (a) total biomass (TB), (b) aboveground biomass (AGB), (c) belowground biomass in the 0-30 $\mathrm{cm}$ soil layer (BGB0-30), (d) belowground biomass in the $0-10 \mathrm{~cm}$ soil layer (BGB0-10), and (e) belowground biomass in the $10-30 \mathrm{~cm}$ soil layer (BGB10-30) to the four precipitation patterns in the lightly degraded (LDG), moderately degraded (MDG) and severely degraded grasslands (SDG). CPF-control precipitation frequency, DPF-the decreased precipitation frequency treatment, CPA-control precipitation amount, IPA-the increased precipitation amount treatment. Different lowercase letters represent significant differences among the precipitation patterns in each grassland. Different uppercase letters indicate significant differences among the degraded grasslands $(P<0.05)$ 

(a)
AGB

Impact-DPF under CPA 2.0

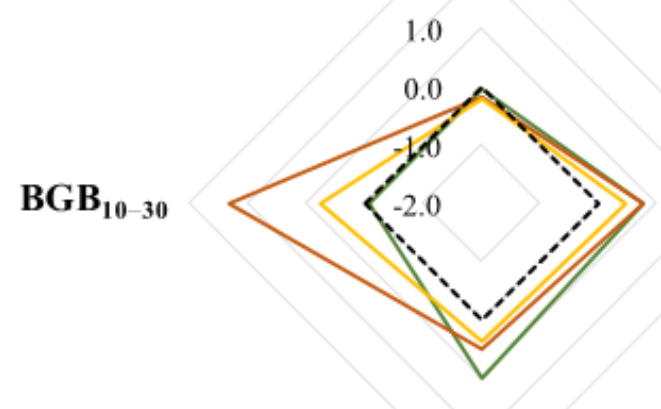

BGB $_{0-10}$

(c)

\section{AGB}

3.0

Impact-IPA under CPF 2.0

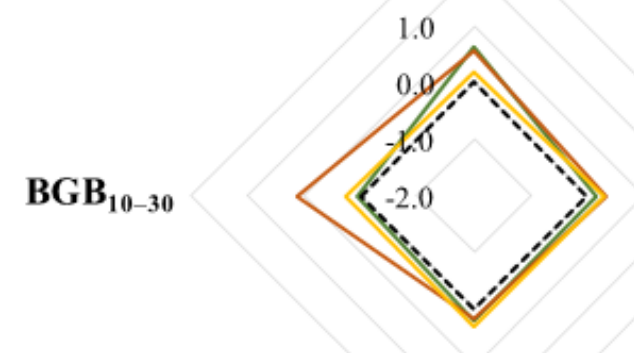

(b) $\quad 3.0$

Impact-DPF under IPA 2.0

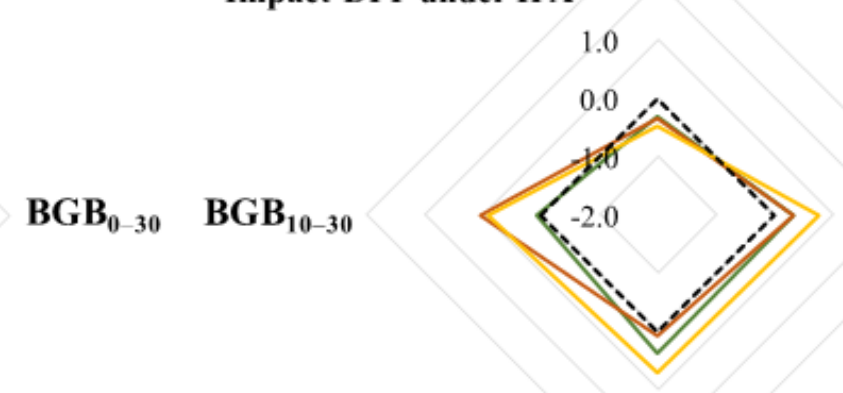

BGB $_{0-30}$

BGB $_{0-10}$

\section{BGB $_{0-30} \quad$ BGB $_{10-30}$}

BGB $_{0-10}$

\section{AGB}

(d) 3.0

Impact-IPA under DPF ${ }^{2.0}$

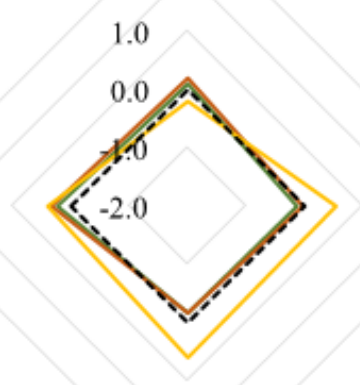

BGB $_{0-30}$

BGB $_{0-10}$

- lightly degraded grassland (LDG)

moderately degraded grassland (MDG)

severely degraded grassland (SDG)

\section{Figure 2}

Summary of the baskets of biomass associated to the different precipitation treatments, presenting the impact values of the decreased precipitation frequency treatment (DPF) and the increased precipitation amount treatment (IPA) on biomass. CPA-control precipitation amount; CPF-control precipitation frequency. AGB-aboveground biomass, BGB0-30, BGB0-10, BGB10-30-belowground biomass in the $0-30,0-10$ and 10-30 cm soil layers, respectively. (a) Impact-DPF under CPA = (XDPF+CPA - XCPF+CPA) / XCPF+CPA, where $X$ represents biomass. (b) Impact-DPF under IPA = (X DPF+IPA $-X C P F+I P A) / X C P F+I P A$. (c) ImpactIPA under $\mathrm{CPF}=(\mathrm{XCPF}+\mathrm{IPA}-\mathrm{XCPF}+\mathrm{CPA}) / \mathrm{XCPF}+\mathrm{CPA}$. (d) Impact-IPA under DPF $=(\mathrm{XDPF}+\mathrm{IPA}-\mathrm{XDPF}+\mathrm{CPA})$ / $\mathrm{XDPF}+\mathrm{CPA}$ 


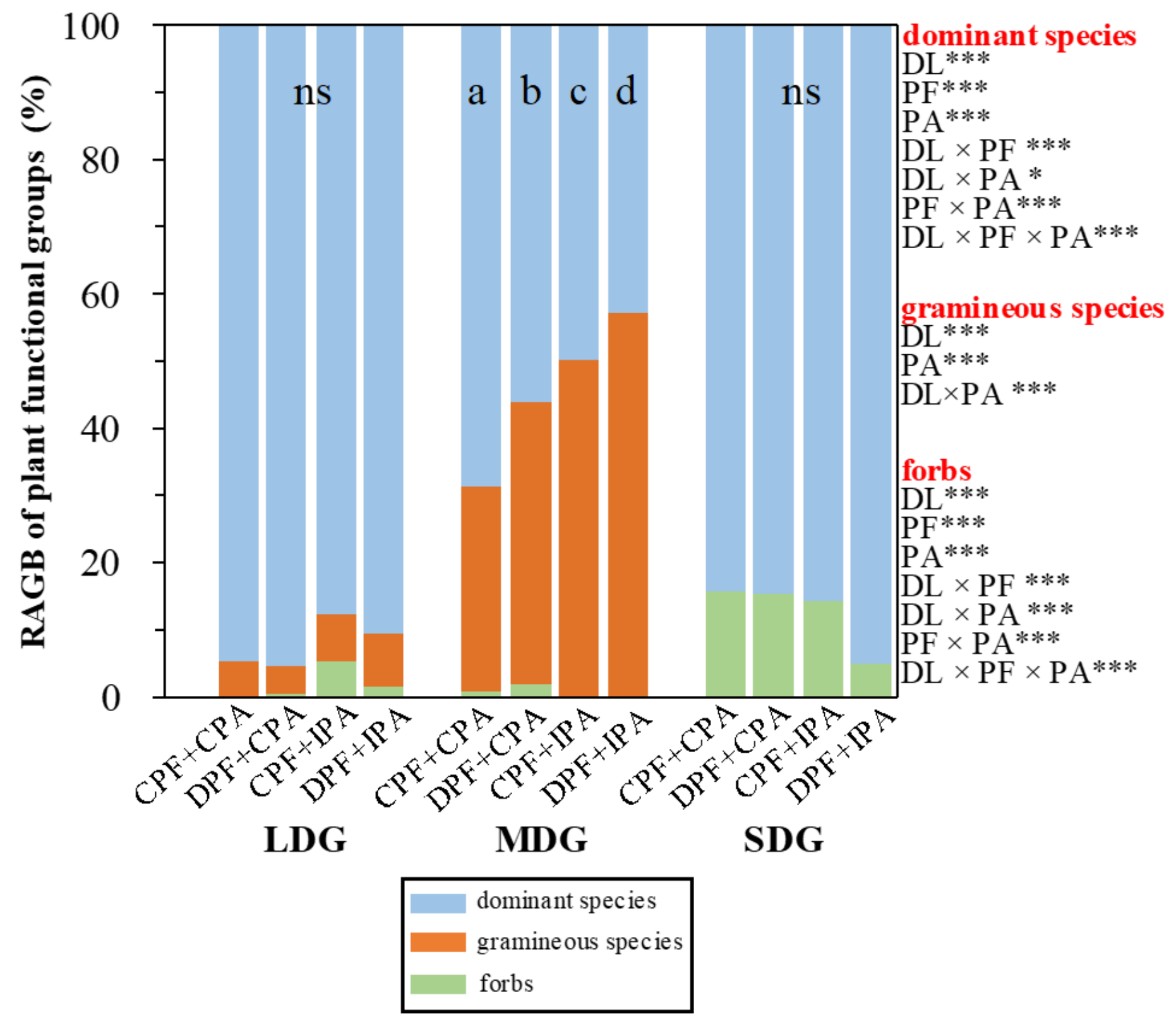

\section{Figure 3}

Relative aboveground biomass (RAGB) of plant functional groups under the four precipitation patterns in the lightly degraded (LDG), moderately degraded (MDG) and severely degraded grasslands (SDG). CPF-control precipitation frequency, DPF-the decreased precipitation frequency treatment, CPA-control precipitation amount, IPA-the increased precipitation amount treatment, DL-degradation level of grassland, PFprecipitation frequency treatment, PA-precipitation amount treatment. Different lowercase letters-significant differences in RAGB of the dominant species among precipitation patterns in each grassland $(P<0.05) .{ }^{*}, * \star$, and $* \star \star$ denote significance at the levels of $\mathrm{P}<0.05, \mathrm{P}<0.01$ and $\mathrm{P}<0.001$, respectively 


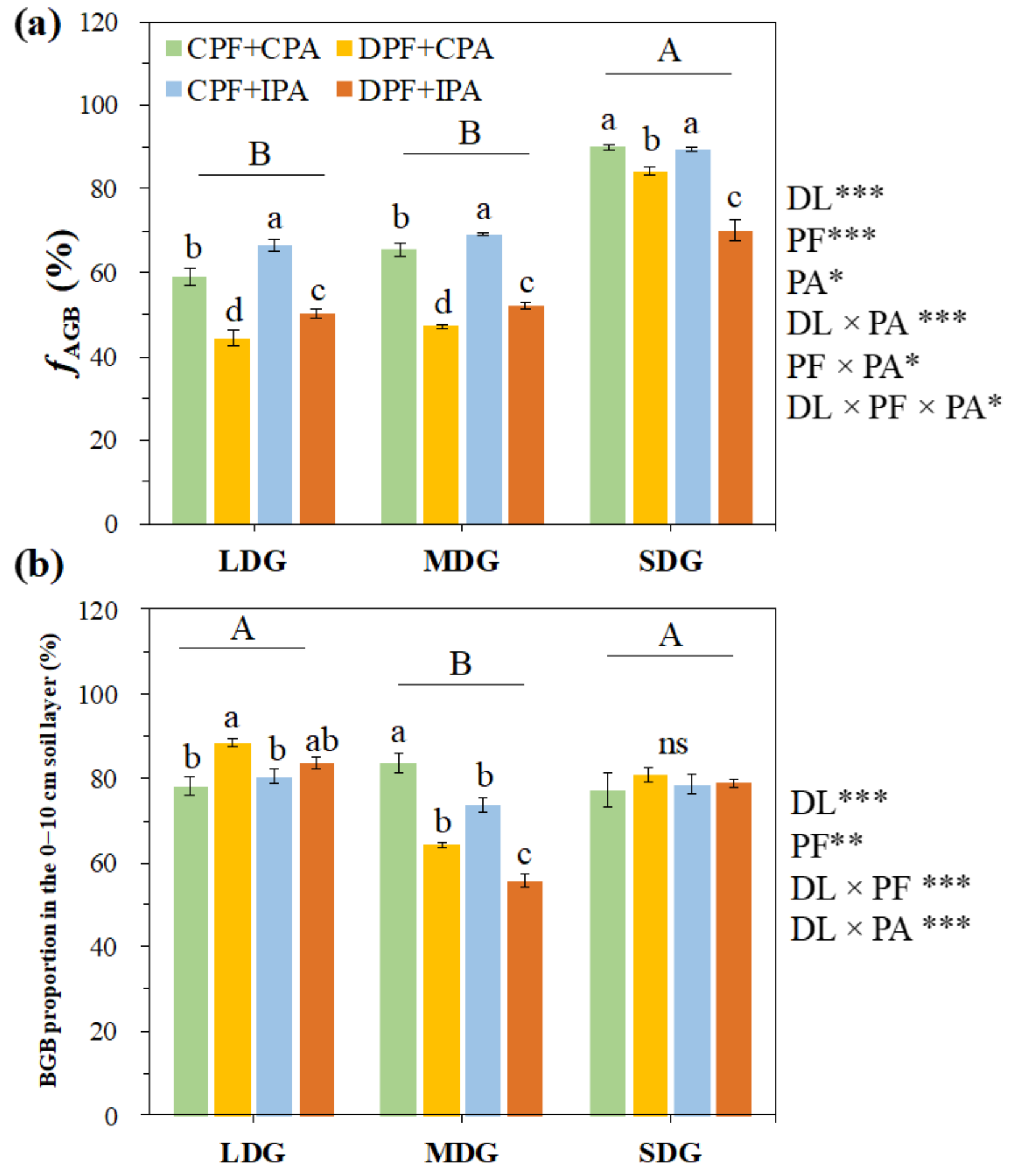

Figure 4

(a) The fraction of aboveground biomass to total biomass (fAGB) and (b) belowground biomass (BGB) proportion in the $0-10 \mathrm{~cm}$ soil layer under the four precipitation patterns in the lightly degraded (LDG), moderately degraded (MDG) and severely degraded grasslands (SDG). CPF-control precipitation frequency, DPF-the decreased precipitation frequency treatment, CPA-control precipitation amount, IPA-the increased precipitation amount treatment, DL-degradation level of grassland, PF-precipitation frequency treatment, PAprecipitation amount treatment. Different uppercase letters-significant differences among the degraded 
grasslands. Different lowercase letters-significant differences among the precipitation patterns in each grassland $(P<0.05)$. * **, and *** denote significance at the levels of $P<0.05, P<0.01$ and $P<0.001$, respectively

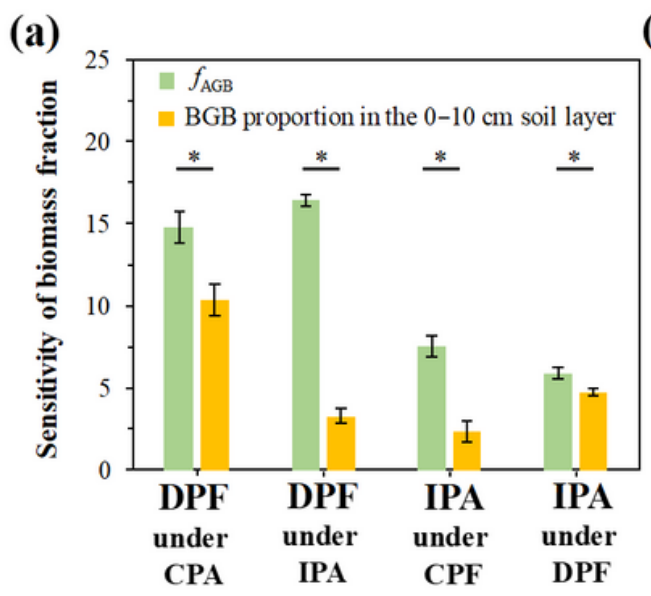

(b)

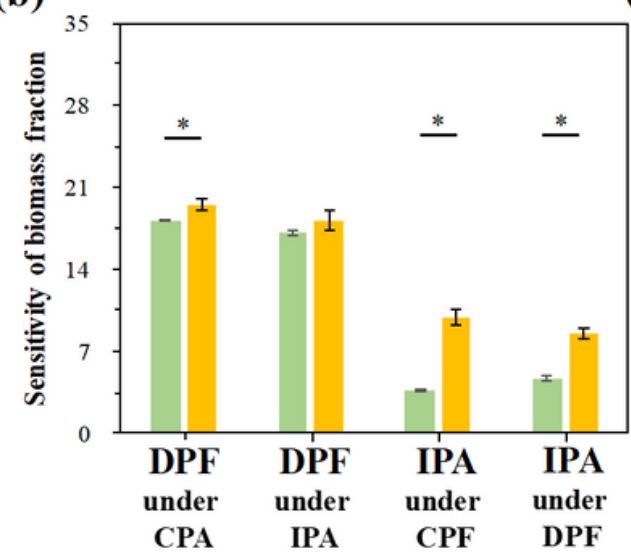

(c)

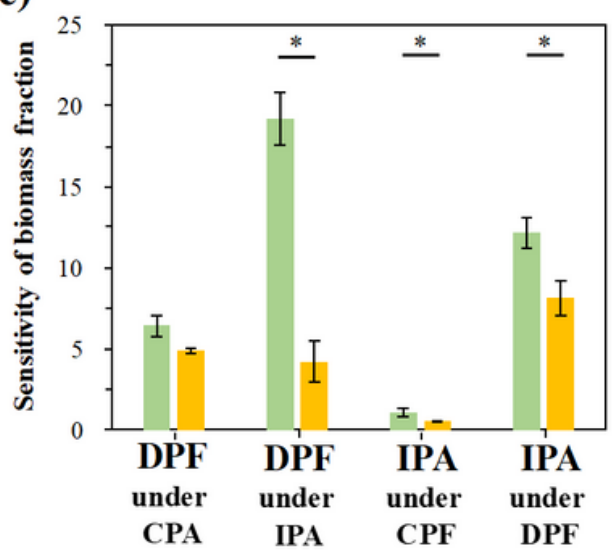

\section{Figure 5}

Sensitivity of the fraction of AGB to total biomass ( $\mathrm{fAGB}$ ) and BGB proportion in the $0-10 \mathrm{~cm}$ soil layer to the altered precipitation patterns in (a) the lightly degraded, (b) moderately degraded, and (c) severely degraded grasslands. Sensitivity of biomass fraction to the decreased precipitation frequency treatment (DPF) under control precipitation amount $(\mathrm{CPA})=|\mathrm{XDPF}+\mathrm{CPA}-\mathrm{XCPF}+\mathrm{CPA}|$, where $\mathrm{X}$ represents biomass fraction.

Sensitivity of biomass fraction to DPF under the increased precipitation amount treatment $($ IPA $)=\mid X D P F+I P A$ - XCPF+IPA|. Sensitivity of biomass fraction to IPA under control precipitation frequency $(\mathrm{CPF})=\mid \mathrm{XCPF}+\mathrm{IPA}$ - XCPF+CPA|. Sensitivity of biomass fraction to IPA under DPF = |XDPF+|PA - XDPF+CPA|. * denotes Independence Samples T-test results between sensitivity of fAGB and sensitivity of BGB proportion in the 0$10 \mathrm{~cm}$ soil layer in an identical condition $(\mathrm{P}<0.05)$
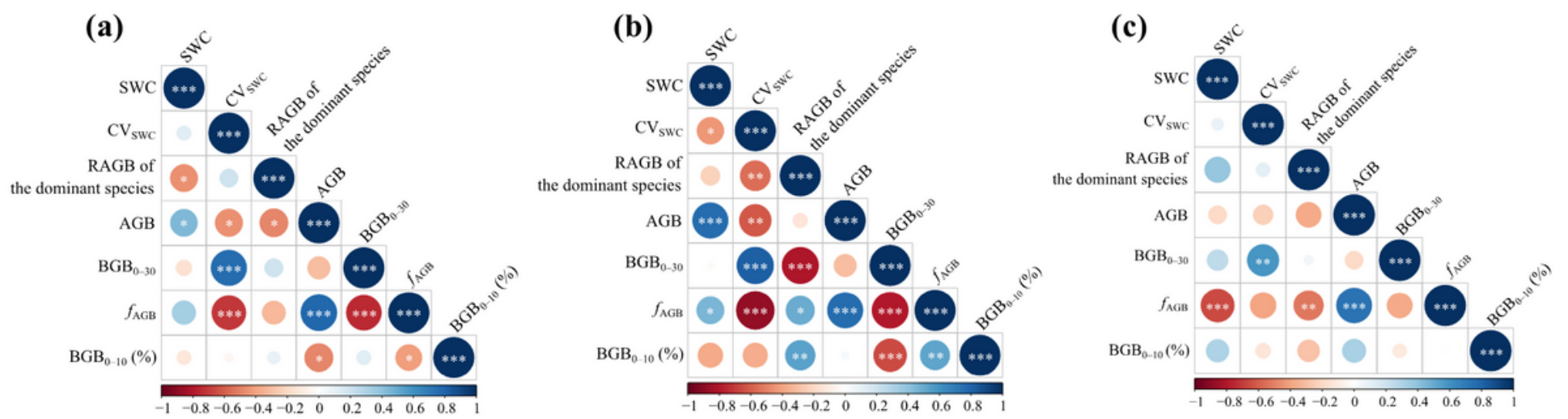

\section{Figure 6}

Pearson correlations between biomass and its allocation, and characteristics of soil water and plant community composition in (a) the lightly degraded, (b) moderately degraded and (c) severely degraded grasslands. SWC and CVSWC-mean and variation of soil water content in the surface soil layer, AGBaboveground biomass, BGB0-30-belowground biomass in the $0-30 \mathrm{~cm}$ soil layer, $\mathrm{fAGB}$-the fraction of AGB 
to total biomass, RAGB-relative ABG, BGB0-10 (\%)-BGB proportion in the $0-10 \mathrm{~cm}$ soil layer. *, **, and *** indicate significance at the levels of $P<0.05, P<0.01$ and $P<0.001$, respectively

\section{Supplementary Files}

This is a list of supplementary files associated with this preprint. Click to download.

- Supplementalfile.docx

- GraphicalAbstract.png 